\title{
The opsin repertoire of the Antarctic krill Euphausia superba
}

\author{
Alberto Biscontin ${ }^{\mathrm{a}}$, Elena Frigato ${ }^{\mathrm{b}}$, Gabriele Sales ${ }^{\mathrm{a}}$, Gabriella M. Mazzotta ${ }^{\mathrm{a}}$, Mathias Teschke ${ }^{\mathrm{c}}$, \\ Cristiano De Pittà a , Simon Jarman ${ }^{\mathrm{d}, \mathrm{f}}$, Bettina Meyer ${ }^{\mathrm{c}, \mathrm{e}}$, Rodolfo Costa ${ }^{\mathrm{a}, *}$, Cristiano Bertolucci ${ }^{\mathrm{b}, * *}$ \\ a Dipartimento di Biologia, Università degli Studi di Padova, Padova, Italy \\ ${ }^{\mathrm{b}}$ Dipartimento di Scienze della Vita e Biotecnologie, Università di Ferrara, Ferrara, Italy \\ c Section Polar Biological Oceanography, Alfred Wegener Institute Helmholtz Centre for Polar and Marine Research, Bremerhaven, Germany \\ d Australian Antarctic Division, Kingston, Tasmania, Australia \\ e Institute for Chemistry and Biology of the Marine Environment, Carl von Ossietzky University of Oldenburg, Oldenburg, Germany \\ ${ }^{\mathrm{f}}$ CIBIO-InBIO, Centro de Investigação em Biodiversidade e Recursos Genéticos, Universidade do Porto, 4485-661 Vairão, Portugal
}

\section{A R T I C L E I N F O}

\section{Article history:}

Received 18 February 2016

Received in revised form 14 April 2016

Accepted 19 April 2016

Available online $\mathrm{xxxx}$

\section{Keywords:}

Antarctic krill

Euphausia superba

Opsins

Nonvisual opsins

Daily rhythms

\begin{abstract}
A B S T R A C T
The Antarctic krill Euphausia superba experiences almost all marine photic environments throughout its life cycle. Antarctic krill eggs hatch in the aphotic zone up to $1000 \mathrm{~m}$ depth and larvae develop on their way to the ocean surface (development ascent) and are exposed to different quality (wavelength) and quantity (irradiance) of light. Adults show a daily vertical migration pattern, moving downward during the day and upward during the night within the top $200 \mathrm{~m}$ of the water column. Seawater acts as a potent chromatic filter and animals have evolved different opsin photopigments to perceive photons of specific wavelengths. We have investigated the transcriptome of $E$. superba and, using a candidate gene approach, we identified six novel opsins. Five are r-type visual opsins: four middle-wavelength-sensitive (EsRh2, EsRh3, EsRh4 and EsRh5) and one long-wavelengthsensitive (EsRh6). Moreover, we have identified a non-visual opsin, the EsPeropsin. All these newly identified opsin genes were significantly expressed in compound eyes and brain, while only EsPeropsin and EsRh2 were clearly detected also in the abdomen. A temporal modulation in the transcription of these novel opsins was found, but statistically significant oscillations were only observed in EsRrh3 and EsPeropsin. Our results contribute to the dissection of the complex photoreception system of E. superba, which enables this species to respond to the daily and seasonal changes in irradiance and spectral composition in the Southern Ocean.
\end{abstract}

(c) 2016 Elsevier B.V. All rights reserved.

\section{Introduction}

Solar light is a complex environmental signal characterized by daily and seasonal changes in daylight, irradiance, wavelength composition, direction and polarization (Björn, 2002). In the aquatic environment, chemical and physical factors modulate the different properties of light (Jerlov, 1968). The wavelength composition varies with depth: longer wavelengths are absorbed rapidly, while shorter wavelengths become predominant until the aphotic zone (Loew and McFarland, 1990). These variations are extreme at high latitudes where the photoperiod changes from continuous daylight in summer to constant darkness in winter.

The Antarctic krill Euphausia superba is a crustacean species with a circumpolar distribution that is exposed to almost all marine photic environments during its life cycle. E. superba have a long and complex

\footnotetext{
* Correspondence to: R. Costa, Dipartimento di Biologia, Università di Padova, Via U. Bassi, 58/B, 35121 Padova, Italy.

** Correspondence to: C. Bertolucci, Dipartimento di Scienze della Vita e Biotecnologie Università di Ferrara, Via L. Borsari, 46, 44121 Ferrara, Italy.

E-mail addresses: rodolfo.costa@unipd.it (R. Costa), bru@unife.it (C. Bertolucci).
}

larval development including three nauplius, three calyptopis and six furcilia stages, before the metamorphosis into juvenile (Hempel and Hempel, 1986). Eggs sink to deep oceanic layers up to $1000 \mathrm{~m}$ and after hatching they start their developmental ascent (Marr 1962). Nauplius stages are found in the aphotic zone below $250 \mathrm{~m}$, whereas the calyptopis I is the first feeding stage to enter to the photic zone. Adults show a daily vertical migration pattern moving downward during the day and upward during the night within the $200 \mathrm{~m}$ water column, from photic to aphotic and vice versa (Godlewska, 1996; Quetin and Ross, 1991).

To perceive photons of specific wavelengths animals have evolved several types of opsin photopigments. Opsins are G-coupled protein receptors localized to the membranes of photoreceptors. Phylogenetic analysis has shown that opsins of bilaterians are grouped in three major clades: c-opsin expressed in photoreceptors with a ciliary morphology as vertebrate rods and cones; $r$-opsin expressed in photoreceptors with rhabdomeric morphology as the ommatidia of arthropods; and Group 4 opsin containing relatively poorly characterized non-visual opsin types from both chordates and invertebrates as peropsins and neuropsin (opsin-5) (Porter et al., 2012). Recently, next-generation sequencing technologies have increased significantly the available 
amount of transcriptomic and genomic data for several animal species. Interestingly, crustacean species have genomes with a highly variable number of opsin genes. For instance, transcriptome analysis of the Ostracoda Skogsbergia lerneri and the Branchiura Argulus siamensis revealed 8 opsin genes (Oakley and Huber, 2004; Sahoo et al., 2013). In contrast, the genomes of the Stomatopoda Pseudosquilla ciliate and the Cladocera Daphnia pulex encode 33 and 46 opsin genes, respectively (Colbourne et al., 2011; Porter et al., 2013). The role of this large number of opsins involved in visual and non-visual photoreception is still largely unknown. However, we could speculate that adaptation to complex marine and freshwater photic environments has occurred through an increase of the number of opsin genes (Feuda et al., 2016; Liegertová et al., 2015).

Given its phylogenetic position and its capacity to inhabit different photic environments, we have investigated the transcriptome of the Antarctic krill E. superba in order to identify novel opsin paralogues. Previous investigations have identified three opsin genes in E. superba (Porter et al., 2007; De Pittà et al., 2013). Here, adopting a qualitative candidate gene approach, we analysed sequences from a de novo assembled transcriptome of krill and we identified 6 novel opsins. Among them five are r-type visual opsins. Crustacea visual pigments are clustered in three main clades, related to their spectral sensitivity: longwavelength-sensitive (LWS), middle-wavelength-sensitive (MWS), and short-wavelength/UV-sensitive (SWS/UVS) (Porter et al., 2007). We found four MWS opsins named EsRh2, EsRh3, EsRh4 and EsRh5 and one LWS opsin named EsRh6. In addition, we have identified a Peropsin homologue. Peropsin is a non-visual opsin member of Group 4 opsins previously described in vertebrates, Cephalochordata and Artropoda and a retinal-photoisomerase activity has been proposed as its main function (Sun et al., 1997; Koyanagi et al., 2002; Nagata et al., 2010; Eriksson et al., 2013; Battelle et al., 2015, Lenz et al., 2014; Henze and Oakley, 2015). Furthermore, using qPCR on RNA isolated from compound eyes, brain and abdomen we detected the tissue expression of the newly identified opsins. Finally, prompted by the different expression levels observed among tissues, we investigated the daily fluctuations of opsin mRNA expression in the head (brain, eye and eyestalk) of krill sampled under natural conditions during the Antarctic summer.

\section{Material and methods}

\subsection{Specimen collection}

For the tissue localization experiments Antarctic krill (E. superba) were caught in East Antarctica (65 $35^{\circ} \mathrm{S}, 141^{\circ} 23^{\prime} \mathrm{E}, 15$ Jan. 2015) during the voyage V2 14/15 with RSV Aurora Australis by oblique hauls of several Rectangular Midwater Trawls, using a pelagic net (RMT 8), in the upper $200 \mathrm{~m}$ of the water column. Immediately after hauling, krill were transferred as quickly as possible into $200 \mathrm{~L}$ tanks located in a temperature constant room at $0{ }^{\circ} \mathrm{C}$ and dim light. Every day $50 \%$ of the water was substituted with fresh pre-chilled seawater to ensure a continual turnover of food and nutrients. Twice a day, dead animals and moults were removed from the tanks (Kawaguchi et al., 2010). After arriving in Hobart, Tasmania (January 25, 2015), krill were delivered directly to the Australian Antarctic Division (AAD) aquarium and kept in a $1670 \mathrm{~L}$ holding tank. The holding tank was connected to a $5000 \mathrm{~L}$ chilled sea water recirculation system. The sea water was maintained at $0.5{ }^{\circ} \mathrm{C}$ and was recirculated every hour through an array of filtration devices. Water quality was monitored continuously. A detailed description of the holding tank system at the AAD and of krill maintenance in the laboratory is described elsewhere (King et al., 2003). Lighting was provided by fluorescent tubes. A PC controlled timer system was used to set a natural photoperiod corresponding to that for the Southern Ocean $\left(66^{\circ} \mathrm{S}\right.$ at $30 \mathrm{~m}$ depth). Krill were fed daily with an algal mixture consisting of the cultured pennate diatom Phaeodactylum tricornutum $\left(1.3 \times 105\right.$ cells $\left.\mathrm{mL}^{-1}\right)$, the cultured flagellates Gemingera sp. $\left(1.9 \times 103\right.$ cells $\left.\mathrm{mL}^{-1}\right)$ and Pyramimonas geldicola $\left(4.9 \times 103\right.$ cells $\left.\mathrm{mL}^{-1}\right)$, as well as Pavlova sp. $\left(2.8 \times 104\right.$ cells $\left.\mathrm{mL}^{-1}\right)$, Isochrysis sp. $\left(1.1 \times 105\right.$ cells $\left.\mathrm{mL}^{-1}\right)$ and Thalassiosira sp. $\left(7.6 \times 103\right.$ cells $\left.\mathrm{mL}^{-1}\right)$, which are concentrated bulk feeds of instant algae mixed with seawater (Reed Mariculture, CA, USA), and a commercial larval food (EZ-Larva mixed with seawater at $0.04 \mathrm{~mL} \mathrm{~L}^{-1}$ ). During sampling (February 26, 2015) the holding tank was exposed to a light:dark regime of $24 \mathrm{~h}$ light and $0 \mathrm{~h}$ darkness with a maximum of $100 \mathrm{~lx}$ light intensity at the surface of the tanks during midday. Sampling was done around midday in the middle of the light phase by catching krill randomly out of the holding tank. Animals were dissected on a cooling element and three different tissues (eyestalks, brain, and abdomen) were immediately transferred to RNA stabilization solution (RNA-later, Life Technologies, CA, USA) for subsequent molecular analyses.

For the temporal expression analysis Antarctic krill were collected in the Ross Sea (longitude: $167^{\circ} 28^{\prime} 81^{\prime \prime} \mathrm{E}-179^{\circ} 54^{\prime} 68^{\prime \prime} \mathrm{W}$, latitude $68^{\circ} 40^{\prime}$ $54^{\prime \prime} \mathrm{S}-77^{\circ} 01^{\prime \prime} 81^{\prime \prime} \mathrm{S}$ ) in January 2004 during the XIX Italian Antarctic Expedition with procedures described in Mazzotta et al. (2010). Adult specimens were caught at different times throughout the 24-hour cycle (local times: 01:00, 06:00, 10:00, 15:00, and 18:00) and stored at $-80{ }^{\circ} \mathrm{C}$ in RNA-later (Life Technologies, CA, USA). Specimens caught at each time point were dissected and total RNA was extracted from the head (including the brain and the compound eyes).

\subsection{Screening of transcriptome for opsins}

To identify new putative opsins we manually inspected a de novo unpublished transcriptome of E. superba, provided by the Australian Antarctic Division (Kingston, Tasmania). Total RNA extracted from Calyptosis I and Furcilia V larval stages was used to produce the cDNA libraries for massive sequencing. The Illumina reads were used for clustering and de novo assembly using Trinity RNA-seq software (Grabherr et al., 2011). We used the default k-mer size of $25 \mathrm{nt}$, we imposed a minimum k-mer coverage of two and it enabled the Jaccard clipping to mitigate falsely fused transcripts. After eliminating adapter sequences and filtering out the low-quality reads, including too short ones (20 nt) and repeats, a total of 223.193 contigs longer than $200 \mathrm{bp}$ were obtained. Assembled contigs ranged in size from 200 bp to $13.460 \mathrm{bp}$, with a median size of $328 \mathrm{bp}$. Each putative transcript was searched locally against the NR database downloaded from the NCBI FTP site on the 8.10.2015 by using Blast-N (against NCBI nucleotide database) and Blast-X (against NCBI protein database and TrEMBL) with an e-value cut-off of 1e-6 (De Pittà et al., 2013). The first five matches from each search were grouped and priority was given to Blast-N results. Alignments characterized by less than $50 \%$ of identity or coverage were discarded, as they were considered poorly informative. All the putative transcripts resulting in at least an opsin description among the first five high scoring pairs were chosen. Blast results were manually inspected to select only the sequences unambiguously identified as putative opsins and not those encoding for others members of the $\mathrm{G}$ protein-coupled receptors family.

\subsection{Phylogenetic analysis}

E. superba opsin cDNA sequences were converted into amino acid sequences using the translate tool by ExPASy Proteomics (http:// www.expasy.org/tools/dna.html) and then aligned with other arthropod opsin sequences obtained from UniProtKB (http://www.uniprot. org) using ClustalW2 (Thompson et al., 1994). A phylogenetic tree was generated using a neighbour-joining algorithm based on the Jones-Taylor-Thornton (JTT) model (MEGA 5.0; Tamura et al., 2007). Confidence in nodes was estimated by 1000 bootstrap replicates. A pairwise deletion algorithm was also used to eliminate any alignment gaps present in the sequence. The tree was rooted using the Homo sapiens VIP receptor 1 as outgroup. 


\subsection{Cloning and sequencing of E. superba opsins cDNA}

To confirm the presence of E. superba opsins mRNA sequences identified in the transcriptome, we cloned and sequenced the complete coding sequences of EsRh2, EsRh3, EsRh4, EsRh5, EsRh6 and EsPeropsin. The sequences were deposited in GenBank (acc. nos EsRh2: KU682720, EsRh3: KU682721, EsRh4: KU682722, EsRh5: KU682723, ESRh6: KU682724 and EsPeropsin: KU682725). First-strand cDNA was synthesized from $1 \mu \mathrm{g}$ of total RNA from head using the SuperScript ${ }^{\mathrm{TM}} /$ FirstStrand cDNA Synthesis Kit (Invitrogen, CA, USA), according to the manufacturer's instructions. The first strand cDNA was used as template for PCR with oligonucleotides designed on krill opsins sequences identified in the transcriptome. The oligos used to obtain full-length opsin transcripts are listed in Table 1 and the following programme was used: $94{ }^{\circ} \mathrm{C}$ for $2 \mathrm{~min}$, followed by 40 cycles of $94{ }^{\circ} \mathrm{C}$ for $30 \mathrm{~s}, 60{ }^{\circ} \mathrm{C}$ for $30 \mathrm{~s}$ and $72^{\circ} \mathrm{C}$ for $1 \mathrm{~min}$, with the addition of a final polymerization step at $72{ }^{\circ} \mathrm{C}$ for $7 \mathrm{~min}$. All primers used to clone opsins were designed using the Primer3 design tool (Untergasser et al., 2012). All the PCR reactions were performed with high-fidelity DNA polymerases in order to minimize PCR-induced errors. The PCR products were cloned using StrataClone PCR Cloning Kit (Agilent Technologies, CA, USA). Full-length $E$. superba opsins cDNA sequence were sequenced with a modified Sanger dideoxy terminator cycle sequencing chemistry, the ABI BigDye kit version 3.1, on an ABI 3730 48-capillary sequencer and $36 \mathrm{~cm}$ capillaries (BMR Genomics Sequencing Service, Italy).

\subsection{Quantitative RT-PCR}

Quantitative RT-PCR was used to localize the expression of opsins. $1 \mu \mathrm{g}$ of total RNA from head, eye and abdomen of single specimens was used to perform independent cDNA syntheses in a final volume of $20 \mu \mathrm{L}$, using a mix of random hexamers and oligodT and SuperScript II reverse transcriptase (Life Technologies, CA, USA). Three biological replicates were analysed. One $\mu \mathrm{L}$ aliquot of 1:4 diluted first-strand cDNA was PCR amplified in $10 \mu \mathrm{L}$ volume using the SYBR Green chemistry according to the manufacturer's recommendations (SsoFast ${ }^{\mathrm{TM}}$ EvaGreen ${ }^{\circledR}$ supermix, Bio-Rad Laboratories, CA, USA) with a CFX Connect Real-Time PCR Detection System (Bio-Rad Laboratories, CA, USA). Thermal cycling conditions were as follows: 3 min denaturation at $95{ }^{\circ} \mathrm{C}$, followed by 40 cycles of a $5 \mathrm{~s}$ denaturation step at $95{ }^{\circ} \mathrm{C}$ and an annealing-elongation step for $20 \mathrm{~s}$ at $60^{\circ} \mathrm{C}$. After amplification, melting curve analysis to confirm the specificity of the amplicon was performed from 60 to $95{ }^{\circ} \mathrm{C}$, with increments of $0.5{ }^{\circ} \mathrm{C} 10 \mathrm{~s}^{-1}$. All samples were run in triplicate. Gene-specific primers designed using the Primer3 design tool (Untergasser et al., 2012) were used to amplify fragments of 120-150 bp in length (Table 1 ). We verified the efficiency of the primers by producing standard curves for all genes investigated. Moreover, the dissociation curve was used to confirm the specificity of the amplicon. The relative levels of each RNA were calculated by the
$2^{-\Delta \Delta C T}$ method (where $C T$ is the cycle number at which the signal reaches the threshold of detection) (Livak and Schmittgen, 2001). As previously reported (Mazzotta et al., 2010; De Pittà et al., 2013), 18S was used as housekeeping gene (QuantumRNA ${ }^{\mathrm{TM}}$ 18S Internal Standards, Ambion, Austin, TX, USA). Each CT value used for these calculations is the mean of three replicates of the same reaction. To ascertain that the apparent changes in the expression of opsins mRNA were not artefacts of normalizing to the $18 \mathrm{~s}$ housekeeping gene, a control experiment was conducted normalizing to another reference gene, the ubiquitin carboxyl-terminal hydrolase 46 (USP46, ID Transcript: N18758 in Meyer et al., 2015; F: 5'-AAATCGTCAGAAACGGGCTA-3', R: 5'-TTAG CGGTTATGGAACATTACG-3', Efficiency $=99.2 \%, \mathrm{R}^{2}=0.989$ ). We used USP46 as a reference gene based on a microarray experiments conducted in our laboratory (data not shown). The expression levels of USP46 were constant during a 24 h experiment in both LD and DD conditions. Furthermore, we tested the reliability of USP46 as housekeeping gene by using three independent algorithms: geNorm (Pattyn et al., 2013), Bestkeeper (Pfaffl et al., 2004), and Normfinder (Andersen et al., 2004). Nearly identical expression profiles were observed when opsins transcript levels were normalized to $18 \mathrm{~s}$ or USP46 mRNA. This method was also used to report on changes in expression of opsins in krill heads (brain and eyes) collected at different time of day (01:00, 06:00, 10:00, 15:00, 18:00). Because data were not normally distributed (D'Agostino-Pearson normality test, $\mathrm{p}<0.05$ ), non-parametric KruskalWallis one-way ANOVA and Dunn's multiple comparison test were used to determine significant differences $(P<0.05)$ between groups (GraphPad Prism 4.0, GraphPad Software, CA, USA). The RAIN nonparametric test with the default settings (independent) was used to detect rhythmicity in 24-h time series of opsins expression (Supplementary Table 1 ). This $\mathrm{R}$ package is capable of detecting both sawtoothshaped and sinusoidal rising and falling patterns (Thaben and Westermark, 2014). We set the sampling interval to $1 \mathrm{~h}$ and the number of replicates for each time point, using the argument named "measure. sequence", in order to detect the periodicity in our irregular time series.

\subsection{Ethics statement}

All animal work has been conducted according to relevant national and international guidelines. Animals were collected both at the Australian Antarctic Division (Hobart, Australia) and during the XIX Italian Antarctic Expedition (2003-2004). Krill fishing was conducted in accordance with the Convention for the Conservation of Antarctic Marine Living Resources (CCAMLR, 1980) under permissions from the Italian Scientific Commission for Antartica (CSA) and the Consortium of Programma Nazionale di Ricerche in Antartide (PNRA, Project N. 2003/1.3 "Molecular neurogenetics of circadian rhythmicity in E. superba"). Export of krill specimens from Australia to Italy was made in accordance with the Department of the Environment, Australian Government (registration number IT111A).

Table 1

Primers used for cloning and quantitative PCR.

\begin{tabular}{|c|c|c|c|c|}
\hline & Primers for cloning & Primers for $\mathrm{qPCR}$ & $\%$ & $\mathrm{R}^{2}$ \\
\hline \multirow[t]{2}{*}{ EsRh2 } & F: 5'-TGGTCAGAAGCTCTGCACTG-3' & F: 5'-TCATCATGGCAAACATCACA-3' & 106.4 & 0.997 \\
\hline & R: 5'-TTTTCATGATTGCTGGGACA-3' & R: 5'-TGTGCCACATTGGATTGACT-3' & & \\
\hline \multirow[t]{2}{*}{ EsRh3 } & F: 5'-GTGGCACGAGGATCTCAAAT-3' & F: 5'-GTGGCACGAGGATCTCAAAT-3' & 100.8 & 0.935 \\
\hline & R: 5'-TGTTTGCTGGGTTATCATGC-3' & R: 5'-GATGGAGGTTCCCTCTGGAT-3' & & \\
\hline \multirow[t]{2}{*}{ EsRh4 } & F: 5'-ATTGCCCATTGGTCATTCAT-3' & F: 5'-GCTCATACACCTTCATAGTC-3' & 94.9 & 0.950 \\
\hline & R: 5'-GCAGTGGTATCAACGCAGAG-3' & R: 5'-CTCTTGACATTCATCTTCTC-3' & & \\
\hline \multirow[t]{2}{*}{ EsRh5 } & F: 5'-TGGCTAGCAGTCAACCAACA-3' & F: 5'-TGGCTAGCAGTCAACCAACA-3' & 104.3 & 0.974 \\
\hline & R: 5'-GGCCACAATGTTGCATTTTA-3' & R: 5'-GTTGTATCCCCCTTCGGAAC-3' & & \\
\hline \multirow[t]{2}{*}{ EsRh6 } & F: 5'-GGAAGAGAGGATACGGACCA-3' & F: 5'-ATTTGTGACTACAAAGAACC-3' & 107.5 & 0.997 \\
\hline & R: 5'-CCTGTTCCCTCAAATCTGGA-3' & R: 5'-GAAAAGACACAGAAGTCATC-3' & & \\
\hline \multirow[t]{2}{*}{ EsPeropsin } & F: 5'-TGGATCCACTAGAAAAACAATGG-3' & F: 5'-GCTATTACCAGAGCGCCAAG-3' & 102.7 & 0.999 \\
\hline & R: 5'-TCGGCTTCTAGGCTATGTGG-3' & R: 5'-CCACAGCATACCATGACCAG-3' & & \\
\hline
\end{tabular}

\%: percentage of efficiency. 


\section{Results}

\subsection{Identification of opsin genes in the trascriptome of E. superba}

Our screening of E. superba transcriptome for opsins resulted in 57 highly redundant contigs. Fifty-four contigs are members of the MWS clade, the other 3 are dispersed among LWS and Group 4 opsin (1 and 2 contigs, respectively). The transcriptome did not contain SWS/UV transcripts. In order to reduce this redundancy we have manually clustered very similar sequences ( $>85 \%$ identity) obtaining 8 unique putative transcripts: 6 newly and 2 previously identified (Rh1a and Rh1b; De Pittà et al., 2013) opsin genes. We successfully cloned sequences of all the new opsin transcripts, which we named according to the clade in which they are located in our phylogenetic analyses (MWS opsins: EsRh2, EsRh3, EsRh4, EsRh5, LWS opsin: ESRh6 and EsPeropsin; Fig. 1). One of the newly found opsins in the E. superba transcriptome is a member of the Peropsin group. It has $48-49 \%$ of amino acid identity with Chelicerata peropsins and 35-39\% with deuterostome homologues (Fig. 2). MWS opsins (ESRh2-Rh5) are $>50 \%$ identical in their amino acid sequences (Fig. 3). EsRh6 and EsPeropsin show 35-38\% and 25-28\% of amino acid identity to MWS opsins, respectively.

All these novel opsins are predicted to be seven transmembrane (TM) domain proteins and possess all the key elements necessary for phototransduction (Gartner and Towner, 1995; Townson et al., 1998): 1 ) the lysine $(\mathrm{K})$ responsible for covalent binding to the chromophore through a Schiff's base interaction in the VIITM domain; 2) two conserved cysteine $(\mathrm{C})$ residues in the I and II extracellular domains, responsible for disulphide linkage stabilization; 3) a glutamic acid (E) to serve as Schiff's base counterion in the II extracellular domain; 4) a potential G-protein binding site (DRY) in the II intracellular domain; 5) the NPXXY motif in the VIITM domain, which is a highly conserved motif among G-protein coupled receptors; 6) a $\mathrm{HPR}(\mathrm{K})$ motif in the C-terminus, characteristic of opsins that activate the $\mathrm{Gq} / 11$ class of GTP-binding proteins (Figs. 2 and 3). Furthermore, E. superba opsins nested within MWS and LWS clade have two residues ( $\mathrm{Y}$ and $\mathrm{S}$ in the IIITM domain) functionally related to the long/middle-wavelength spectral sensitivity (Chang et al., 1995) (Fig. 3).

\subsection{Localization and temporal expression of E. superba opsin trascripts}

To investigate the expression at the mRNA level of opsin genes in different tissues of E. superba, we performed qPCR using RNA from dissected brain, eye and abdomen (Fig. 4). The newly identified opsins were all expressed, albeit with some differences in the expression levels, in compound eyes and brains, while only EsPeropsin and EsRh2 were clearly detected in the abdomen (Fig. 4C).

As we had previously observed a daily variation of EsRh1a and EsRh1b mRNA expression in the head of Antarctic krill collected under natural conditions (De Pittà et al., 2013), we investigated the temporal expression of the novel opsins detected in the E. superba transcriptome. qPCR was performed on specimens collected in the Ross Sea at different times of the day (01:00,06:00, 10:00,15:00, and 18:00) during the Antarctic summer (Mazzotta et al., 2010), when they were exposed to an almost continuous $24 \mathrm{~h}$ photoperiod characterized by daily variations in solar irradiance (Fig. 5). qPCR showed a general high inter-individual variability in opsin levels, consistently with the fact that no significant temporal patterns of expression were detected by ANOVA (EsRh2: $\mathrm{H}_{5}=2, \mathrm{p}>0.7 ; E s R h 3: \mathrm{H}_{5}=9.1, \mathrm{p}=0.06 ;$ EsRh4: $\mathrm{H}_{5}=4.8, \mathrm{p}>0.3 ;$ EsRh5: $\mathrm{H}_{5}=4.9, \mathrm{p}>0.3 ;$ EsRh6: $\mathrm{H}_{5}=4.3, \mathrm{p}>0.3$; EsPeropsin: $\left.\mathrm{H}_{5}=9.2, \mathrm{p}>0.05\right)$. However, the overall data suggest the

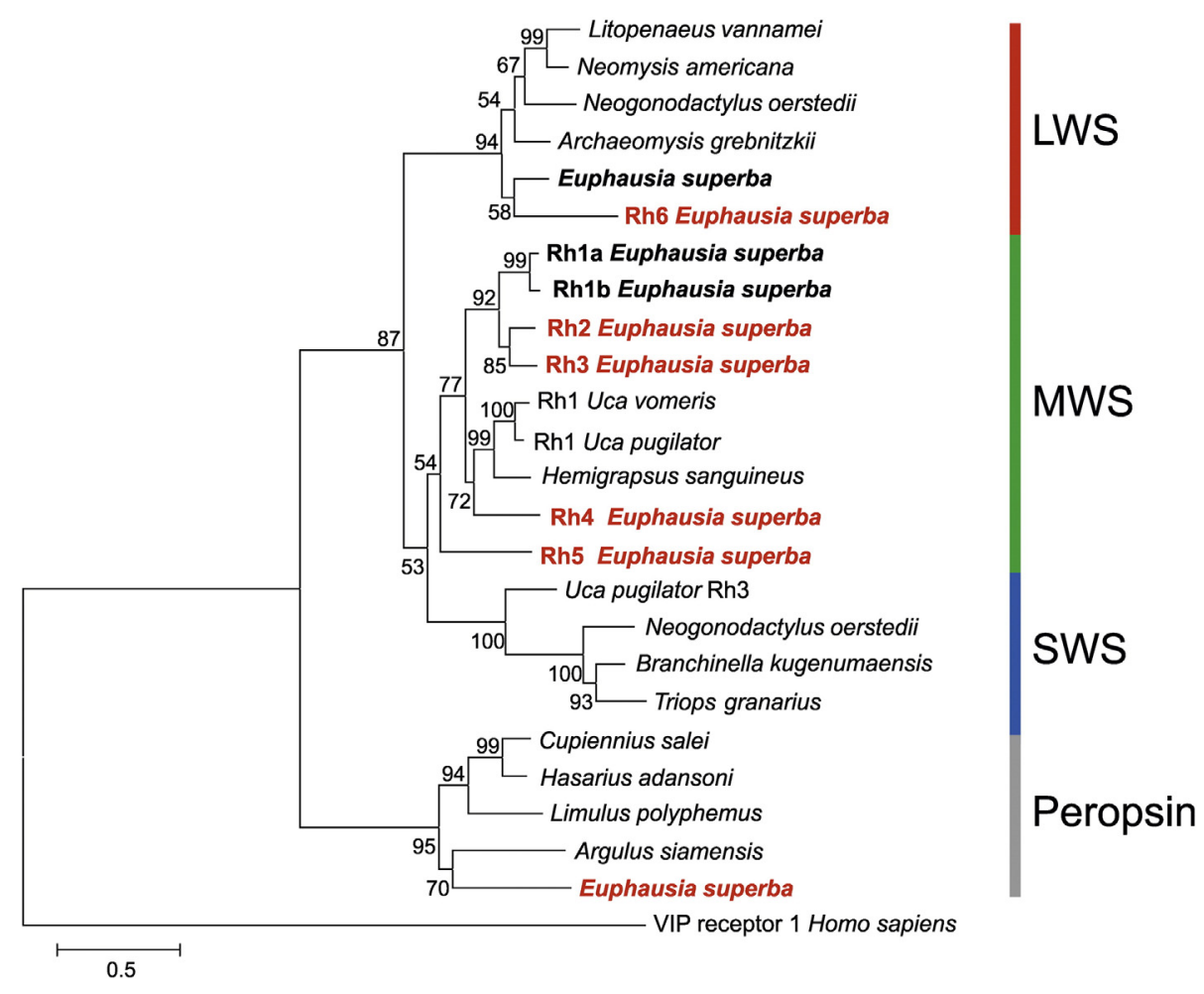

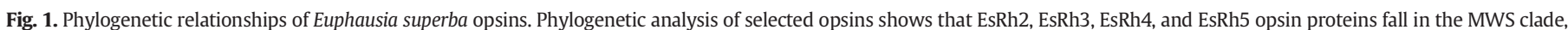

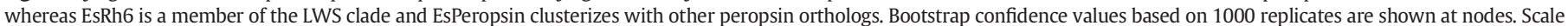

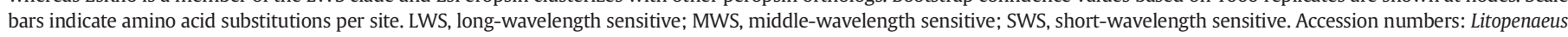

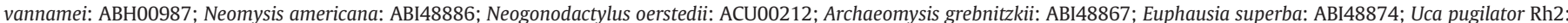

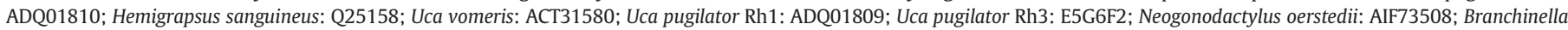

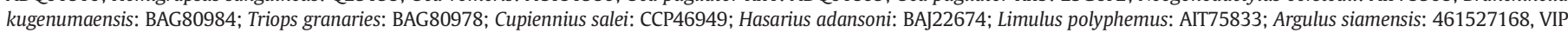
receptor 1 Homo sapiens: P32241. 


\section{C.salei \\ H. adansoni \\ I.polyphemus \\ E. superba \\ B.belcheri \\ M.musculus}

C.salei

H. adansoni

I.polyphemus

E. superba

$B$.belcheri

M.musculus

\section{C.salei \\ H. adansoni \\ L.polyphemus \\ E. superba \\ $B$.belcheri \\ M.musculus}

\section{C.salei \\ $H$. adansoni \\ L.polyphemus \\ E. superba \\ $B$.belcheri \\ M.musculus}

$$
\begin{aligned}
& \text { C.salei } \\
& \text { H.adansoni } \\
& \text { L.polyphemus } \\
& \text { E. superba } \\
& \text { B.belcheri } \\
& \text { M.musculus }
\end{aligned}
$$

I MDDNMSE IALADDMSTLSTQEPSENVYPY----VEPLSTHTIVGTYLI I IGILGTLGNGLVLVTELRERVLVTPTTLLLVNLAVSDLGLI MASSTELGSVDLNMSLGETPE EQADKDTYLVDSTEPTSTHKAVGI YLVIVGI LGTFGNGI I ITME IRERTLLTPTNLLLITLAVSDLGI I 作 MDI PTETPYGAEEDIGESAGWRWTETDKN----GEHKYDHLIVGLYLFVIGI IGTIENGITLATFSKERSLRSPTTMLLVHLAIADLGIC ------------MLSEASDFNSSGSRSEGSVESRTEHSVIAAYLIVAGITS I LSNVVVLGI F IKYKELRTPTNAVI INLAFTDIGVS

III IV

LFG-FPESSSSSFSGRWLFGDGGCOWYAEMGFLFGSAHIGTLTILALDRYLIACR--------ISLRGKLTYRRYTOMLSAVWAYAMFWS 168 LFG-FPFSASSSLSAKWIFGEGGCQWYAEMGFLFGSAHIGTLALLALDRYLIACR--------ISLRGKLTFKRYTQMITVVWTYAFFWA 168 LFG-FPFSASSSFANRWLFNEGGCOWYAEMGFLFGSAHIGVLALLGLDRYLITCR--------IDFRRKLTYKRYCOMICAVWVYAI FWS 172 LMGGFPFSGTSSFAGKWLWGEWGCQYYAFMGFFFGIGNLTTILMIALDRYLVTCRQDLKLREGVDLGDKLNYSRYIQMITFIWTWSFFWA 156 IFG-YPFSGASSLRSHWLFGGVGCQWYGENGMFFGMANIGLLTCVAVDRYLVICR--------HDLVDKVNYNTYGVMAALGWLFAAFWA 168 SIG-YPMSAASDLHGSWKFGHAGCQIYAGLNI FFGMVSIGLLTVVAMDRYLTISCP--------DVGRRMTTNTYLSMILGAWINGLFWA 156

$\mathrm{V}$

LMPLIGWTGRYGE PSVTTCTI DWQHNDSSYKSFI IVYFVLGFLVPFAIIAVCYCAIARRALMPLIGWGRYGLEPSVTTCTIDWQHNDSSY 258 LMPLLGWGRYGLE PSVTTCTI DWQHNDSSYKSFLIVY FVLGFMVPEAI IAVSYIAIARRVLMPLLGWGRYGLEPSVTTCTIDWQHNDSSY 258 VMPLIGW̄GRYGPEPSITTCTI DWRHNDGSYKSFI IVYFVLGFLVPFLLIAICYFNIARQLVMPLIGWGRYGPEPSITTCTIDWRHNDGSY 262 VCPLLGWARYGYEPSVTTCTLDWQHNDSSYKSYIMMASIMVYMVPCMIMTSCYYQSAKYLVCPLLGWARYGYEPSVTTCTLDWQHNDSSY 246 ALPLVGWAEYALE PSGTACTINFQKNDSLYISYVTSCFVLGFVVPLAVMAFCYWQASCFVALPLVGWAEYALEPSGTACTINEQKNDSLY 258 LMPI I GWASYAPDPTGATCTI NWRNNDTSFVSYTMMVIVVNEIVPLTVMFYCYYHVSRSLLMPI IGWASYAPDPTGATCTINWRNNDTSF 246

VI

KSFI IVY FVLGFLVPFAIIAVCYCAIARRARRKVKE--------RAVVRDQWTNERNVTLMSFILIVAFVVAWSPYAVLCLWTIFAPPST 340
KSFLIVYFVLGFMVP FAI IAVSYIAIARRVGKKSKE-------RPVVRDLWTNERSVTLMAFILIVTFFVAWSPYAVLCLWTIFAEPNT 340
KSFI IVYFVLGFLVPFLLIAICYFNIARQLSVKPVAPSL-----RSAICDQWANERNVTMMCLVIVITFVVSWSPYAIVCLWTVFKPPST 347
KSYIMMASIMVYMVPCMIMTSCYYQSAKYLRQARKQG------NSTIKYDWATESNVNKMGIILIAAYLICWSWYAVVCIWVVRDPKT 329
ISYVTSCFVLGFVVPLAVMAFCYWQASCEVSKVLKGDIAGDLTFPVAANVDWEYQNHFSKMCLAMVAAFVVAWTPYSVLFLFAAFWNPAD 348
VSYTMMVIVVNFIVPLTVMFYCYYHVSRSLRLYAASD------CTAHLHRDWADQADVTKMSVIMILMFLLAWSPYSIVCLWACFGNPKK 330

VII

APPELTLIPPLFAKSSTVLNPLIYFLTNPKLRAAILSTMACCKEAPLQNIELPDSPERAAN-ADAI---------- 405 VPPELTLIPPLFAKSSTVVNPLIYFLSNPKLRTAILSTLSCCNEAPIQNIELPDSPERAAN-NDAI----------- 405 VPSVLTLI PPLFAKASTVFNPI IYYLTNPRLRMGI IATITCSGELPGEMI PVSSNPEATPETHESI----------- 413 VPMILTLLPPLMAKASPVLNPI IYFYANPTLKKGMIATLCCWCHDPPQEL-LEDTPESKRK-------------- 389 I PAW LTLLPPLIAKSSALYNPI IYI IANRR FRNAICSMMKGQDPDVEDDEHADEHRVRSIEDNDKEI ISMVNLNMTV 425 I PPSMAI IAPLFAKSSTFYNPCIYVAAHKKFRKAMLAMFKCQPHLAVPEPSTLPMDMPQSSLAPVRI---------- 397 \$\$\$

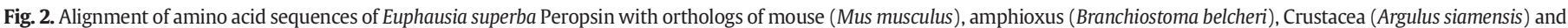

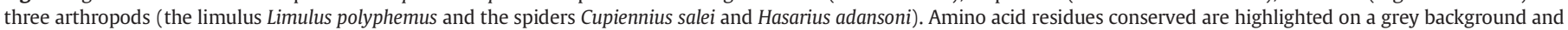

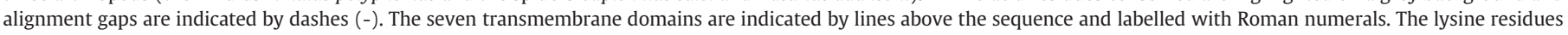

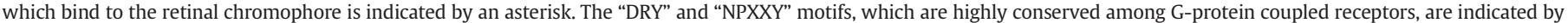
symbols + and \$, respectively.

existence of a temporal modulation of the amplitude and phase of expression for all the novel opsins (Fig. 5). Indeed, EsRh2, EsRh3 and EsRh5 showed maximum levels at 06:00 (Fig. 5A-B, D), whereas EsRh4 and EsRh6 (Fig. 5C, E) reached the peak in the second half of the daylight (15:00-18:00). Conversely, EsPeropsin shows its peak in the middle of the night, at 01:00, when solar irradiance reaches the lowest levels (Fig. 5F). A further analysis performed with RAIN, a robust non-parametric method for the identification of rhythms in biological time series (Thaben and Westermark, 2014), showed that a significant sinusoidal pattern of oscillation actually exists in the case of Peropsin and EsRh3 ( $p=0.0195$, Phase: 01:00 and $p=0.0016$, Phase: 06:00, respectively).

\section{Discussion}

Using a transcriptomic approach, we significantly expanded our knowledge of the opsin repertoire in the Antarctic krill E. superba. Based on phylogenetic affiliations, we identified 5 visual r-opsins belonging to the MWS and LWS clades and a non-visual opsin member of the Peropsin group. The expression of many opsins in the photoreceptor system seems to be common in crustaceans where many species express more opsins than expected based on their photoreceptor physiology. For instance, Stomatopoda and Cladocera species have more than 30 opsins, belonging to different classes, expressed in their transcriptomes. Visual opsins form three evolutionarily distinct groups that generally correlate with the maximum wavelength absorption (LWS, MWS and SWS/UVS; Porter et al., 2007, 2012). Krill opsins identified until now belonged to LWS and MWS clades. Interestingly, none of the contigs that we identified was member of the SWS/UVS clade. This is quite an unexpected result as maintenance of blue sensitivity is likely to be dependent on the photic environment of the species and adult Antarctic krill show a daily vertical migration pattern along the water column below $30 \mathrm{~m}$, where only the blue wavelengths penetrate (Godlewska, 1996). However, another crustacean species phylogenetically closely related to the Antarctic krill, the stomatopod Hemisquilla californiensis, living the blue wavelengths range $(10-50 \mathrm{~m})$, showed in the transcriptome only one transcript annotated as member of SWS/UVS clade (Porter et al., 2013). We expect that an increased depth of coverage of sequencing would identify additional opsin/s in E. superba, with the maximum wavelength absorption in the short wavelengths spectrum.

Non-visual opsins have been detected in invertebrates. For instance a non-visual c-opsin, named pteropsin, has been identified in the brain of the honey bee Apis mellifera (Velarde et al., 2005). Neuropsin (opsin-5) orthologs have been found in the genomes of the tardigrade Hypsibius dujardini (Hering and Mayer, 2014) and of the echinoderm Amphiura filiformis (Delroisse et al., 2014). In the present investigation we have detected in the transcriptome of E. superba a transcript of the nonvisual opsin Peropsin gene. Peropsin has been originally described in human retina (Sun et al., 1997) and further experiment in lancelets demonstrated its photoisomerase activity (Koyanagi et al., 2002). Peropsin orthologs have been identified and characterized in different Chelicerata (spiders Hasarius adansoni and Cupiennius salei, horseshoe 
MANITGPQAMAYGGGPMEVTFGYPEGTSIIDIQHDYMKPLIDPHWRNEP PVNPMNHNLLGVITTFIVFFAVTGNSMVVWLFNKHAPLRTP MANI TGPQAMAYGGG-QEFTFGYPEGTSI IDIQPDYMKAI I DPHWAKFP PVNPMNHYVLGLLYI FIVFFAVTGNFLVIWLFNKHAPLRTP ---MAAPG----------FGYPEGTKI TDFVPAEI LPLVHEHWYQFP PVNPMNHELLGCIYIVMGFWSI LGNGVVVYLFFKSDTLKTP MNETEGPMAEAYGSE-GGYNMGYPAGVTI I DMVPDHI KHMVHPHWANYP PVNPMNHYLLGMVYVILGFFSFTGNGLVMYLFFNHANLRTP WTLAMI SADRYNVICNGFNGPKLTKGKAGVMSLTC ANKLI FNLTFSDFCMMLSQFPWEAYNCFNGGVWSESPFACEL

IV $\mathrm{V}$

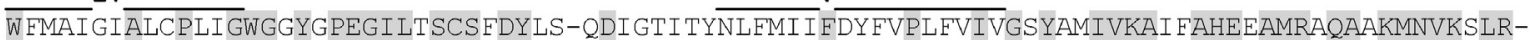
WTLSCTIASLPFFGWGSYGPEGILTSCSFDY IS-QDIGTI TYNLFMFI FNYCCPLII I VGSYAMIVKAI FAHEEAMRAQAAKMNVKSLRWAMAI GWAI PP FVGWGKYI PEGILDSCSYDYLT-LDTNTRSYNMCI FAFDE FVPLFI IVGSYTEIVKAICAHEAAMRKQAEKMNVKSLRWGYATMMAVPP FFGWGKYI PEGI LDSCSFDYLTRDDIMI RTHGMALIVENFCI PVTII I GAYVMIVKAVTAHESAMRAQAAKMNVKDLRG $\begin{array}{lll}\# & £ \\ \mathrm{VI} & \mathrm{VII}\end{array}$

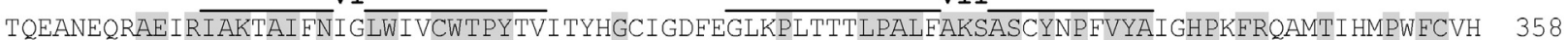
SAEANEQRAEIRIAKTAI FNIALWI ICWTPYAAITLQGCVGREDHLKPLTTTLPALLAKSASCYNPFVYAIGHPRERQAMTI HMPWFCVH 357 SGDDSAESAEIRIAKTAI FNICLWLCCWTPYALVTLMGVLGRHDNI TPLMTMLPALLAKSASCYTPFVYAVGHPKFRQGITIHMPWFCIT 343 NADANKMSAEVRI AKVAICNVTLWLICWTPYAKIVAQGVFFDQSSITPIASMLPAIIAKSASGYNPVVYAINHPRFRLAMTKSFPGFCVH 359

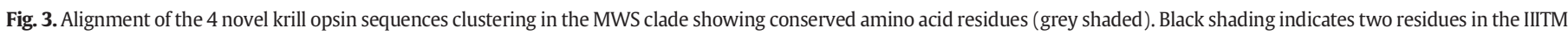

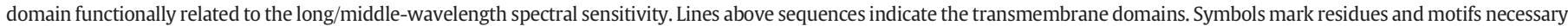
for phototransduction (for more details see results and legend to Fig. 2).

A
EATKT----ADNES-----STTAATEEKA
ENTPQ----ADNQS-----AAT-ATEEKA
EDTPKKLAPTDNKSDGDNSTOPGDTAEKA
ENEPDN---ASTAT-----EANTTQEEKA $\$ \$ \$ \$ \quad \S \S \S$

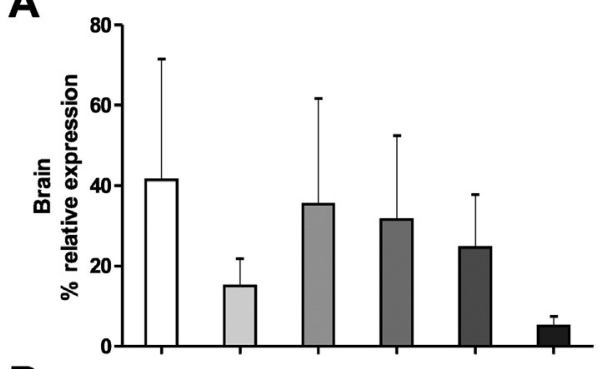

B

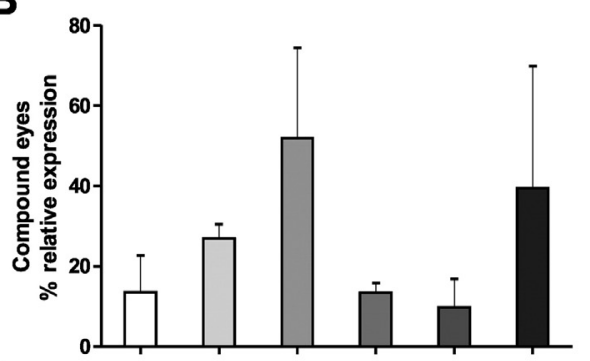

C

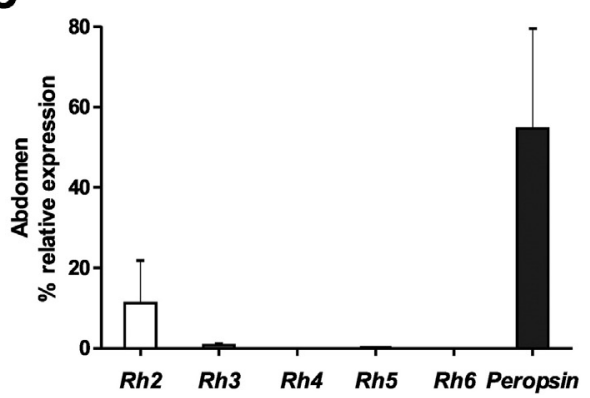

Fig. 4. Relative expression levels of Euphausia superba opsins in brain, compound eyes and abdomen. crab Limulus polyphemus; Nagata et al., 2010; Eriksson et al., 2013; Battelle et al., 2015) and Crustacea (the Branchiura A. siamensis and the Copedoda Calanus finmarchicus; Sahoo et al., 2013; Lenz et al., 2014) species. Interestingly, EsPeropsin is expressed both in eye and in abdomen. The expression in the compound eyes suggests the hypothesis that it could play a role in vision as retinal photoisomerase. However, the expression in the abdomen seems to indicate that it has not (if any) exclusively a role as a photoisomerase, but it could also work as a photoreceptor. The expression of opsins in the crustacean abdomen has been previously reported. The crayfish Procambarus clarkii has a well-characterized extraocular photoreceptor, called the caudal photoreceptor, located in the sixth abdominal ganglion. SWS and LWS opsin transcripts have been observed not only in the sixth abdominal ganglion, but also in all ganglia of the nerve cord (Kingston and Cronin, 2015). The functional role of the caudal photoreceptor is extended to the triggering of the tail reflex, and to the walking behaviour of the animal. Furthermore, because the abdomen of the Antarctic krill presents photophores, which are used for counterillumination, a common and successful cryptic strategy, we cannot exclude an involvement of the abdominal photoreceptors in a feedback mechanism controlling the irradiance of the light emitted by photophores (Grinnell et al., 1988).

We had previously observed daily rhythms in the expression of the krill opsins EsRh1a and EsRh1b, with a peak of expression at 06:00, in specimen exposed to natural lighting conditions, despite high levels of inter-individual variability (De Pittà et al., 2013). In the present study, the use of a robust non-parametric method specifically designed for the identification of biological rhythmicity allowed us to detect a significant sinusoidal pattern of oscillation for two out of the six newly identified opsins, namely EsPeropsin and EsRh3. Interestingly, EsPeropsin and $E s R h 3$ have different pattern of expression and peak at different time of day (01:00 and 06:00, respectively). Different daily expression profiles of opsins with different spectral sensitivity could be important for the Antarctic krill to entrain their physiological, metabolic and behavioural processes to the daily changes in irradiance and spectral composition of sunlight that occur in the Southern Ocean throughout the seasons (Gaten et al., 2008; Teschke et al., 2011; De Pittà et al., 2013). 

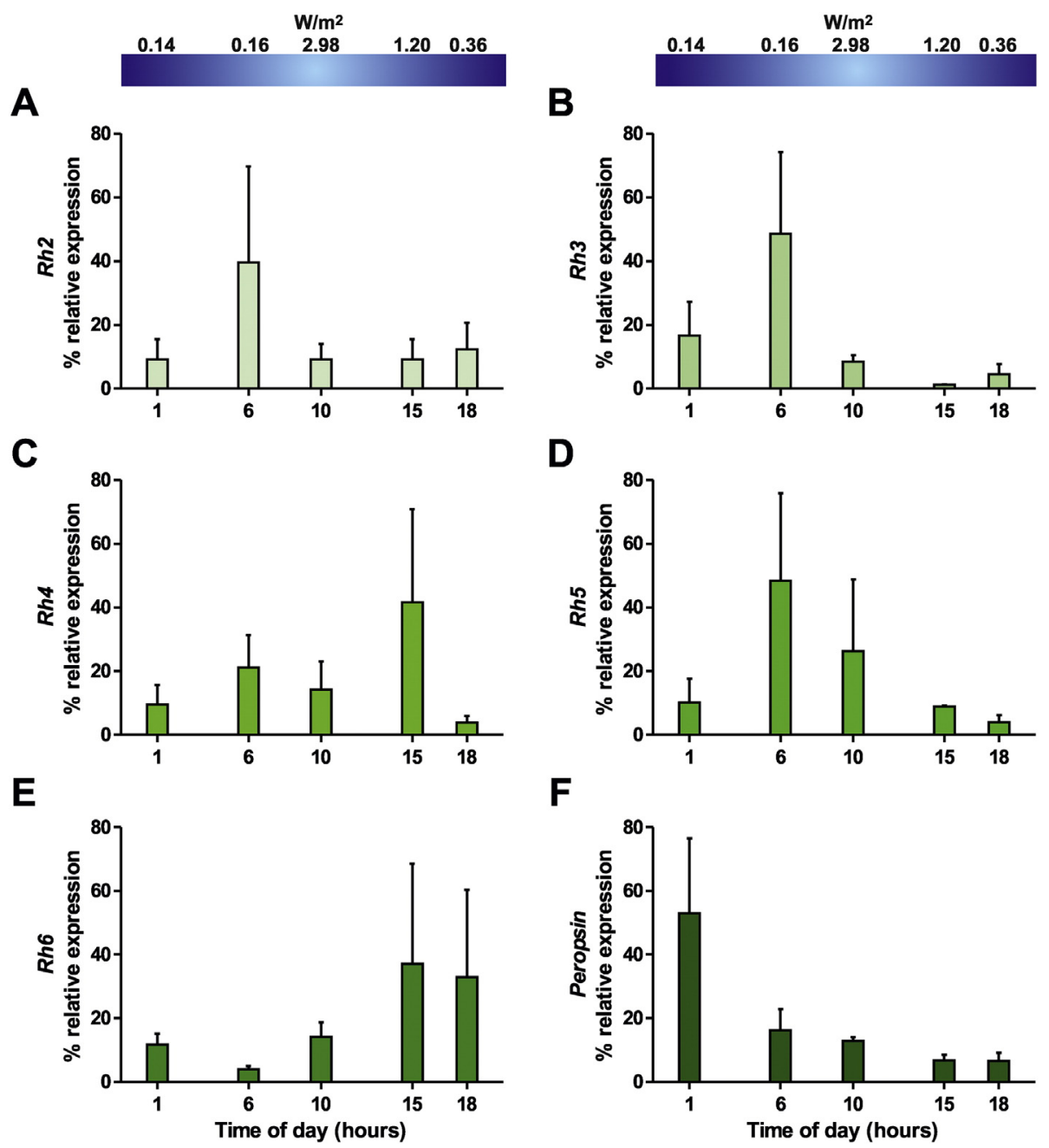

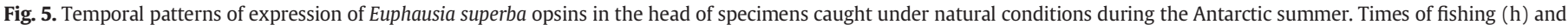

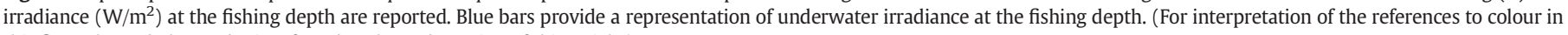
this figure legend, the reader is referred to the web version of this article.)

In summary, we have extended our knowledge on the E. superba opsin repertoire, including the discovery of a non-visual opsin. The future identification of other opsins as pteropsin (c-opsin), arthropsin (r-opsin) and neuropsin (group 4 opsin) could permit further reconstruction of the set of E. superba opsins and interpretation of the complex behavioural responses of krill to changes in illumination during the daily vertical migration and during the seasonal changes of sun irradiance.

Supplementary data to this article can be found online at http://dx. doi.org/10.1016/j.margen.2016.04.010.

\section{Competing interests}

The authors declare that they have no competing interests.

\section{Authors' contributions}

$\mathrm{CB}$ and RC conceived and designed the experiments. $\mathrm{AB}, \mathrm{EF}, \mathrm{CDP}$, and GM performed the experiments. MT and SJ collected the specimens. GS, $A B, C B, S J, B M$ and $R C$ analysed the data. CB, RC, MT, AB, BM and EF wrote the paper.

\section{Acknowledgements}

We thank Antonello Sala (National Research Council, Institute of Marine Sciences, Ancona, Italy) for his help in collecting samples for the temporal expression analysis. This work was supported by the Italian Programma Nazionale di Ricerche in Antartide - PNRA (grant 2013/C1.05 to RC and CB) and the Helmholtz Virtual Institute "PolarTime" (VH-VI-500: Biological timing in a changing marine environment - clocks and rhythms in polar pelagic organisms). This project is also a contribution to the research programme PACES II (topic 1, workpackage5) of the Alfred Wegener Institute. CB acknowledges research grants from the University of Ferrara (FAR2014).

\section{References}

Andersen, C.L., Ledet-Jensen, J., Ørntoft, T., 2004. Normalization of real-time quantitative RT-PCR data: a model based variance estimation approach to identify genes suited for normalization - applied to bladder- and colon-cancer data-sets. Cancer Res. 64, $5245-5250$.

Battelle, B.A.A., Kempler, K.E., Saraf, S.R., Marten, C.E., Dugger, D.R., Speiser, D.I., Oakley, T.H., 2015. Opsins in limulus eyes: characterization of three visible light-sensitive opsins unique to and co-expressed in median eye photoreceptors and a peropsin/ RGR that is expressed in all eyes. J. Exp. Biol. 218, 466-479.

Björn, L.O., 2002. Photobiology: The Science of Light and Life. Springer, Netherlands. 
Chang, B.S.W., Crandall, K.A, Carulli, J.P., Hartl, D.L, 1995. Opsin phylogeny and evolution: a model for blue shifts in wavelength regulation. Mol. Phylogen. Evol. 4, 31-43.

Colbourne, J.K., Pfrender, M.E., Gilbert, D., Thomas, W.K., Tucker, A., Oakley, T.H., Tokishita, S., Aerts, A., Arnold, G.J., Basu, M.K., 2011. The ecoresponsive genome of Daphnia pulex. Science 331, 555-561.

De Pittà, C., Biscontin, A., Albiero, A., Sales, G., Millino, C., Mazzotta, G.M., Bertolucci, C., Costa, R., 2013. The Antarctic krill Euphausia superba shows diurnal cycles of transcription under natural conditions. PLoS One 8 (7), 17, e68652.

Delroisse, J., Ullrich-Lüter, E., Ortega-Martinez, O., Dupont, S., Arnone, M.I., Mallefet, J., Flammang, P., 2014. High opsin diversity in a non-visual infaunal brittle star. BMC Genomics 15, 1035.

Eriksson, B.J., Fredman, D., Steiner, G., Schmid, A., 2013. Characterization and localization of the opsin protein repertoire in the brain and retinas of a spider and an onychophoran. BMC Evol. Biol. 13, 186-196.

Feuda, R. Marlétaz, F., Bentley, M.A., Holland, P.W., 2016. Conservation, duplication, and divergence of five opsin genes in insect evolution. Genome Biol Evol. 8 (3), 579-587.

Gartner, W, Towner, P, 1995. Invertebrate visual pigments. Photochem. Photobiol. 62 , $1-16$.

Gaten, E., Tarling, G., Dowse, H., Kyriacou, C., Rosato, E., 2008. Is vertical migration in Antarctic krill (Euphausia superba) influenced by an underlying circadian rhythm? J. Genet. 87 (5), 473-483.

Godlewska, M., 1996. Vertical migrations of krill (Euphausia superba DANA). Pol. Arch. Hydrobiol. 43, 9-63.

Grabherr, M.G., Haas, B.J., Yassour, M., Levin, J.Z., Thompson, D.A., Amit, I., Adiconis, X., Fan, L., Raychowdhury, R., Zeng, Q., Chen, Z., Mauceli, E., Hacohen, N., Gnirke, A., Rhind, N., Di Palma, F., Birren, B.W., Nusbaum, C., Lindblad-Toh, K., Friedman, N., Regev, A., 2011. Trinity: reconstructing a full-length transcriptome without a genome from RNA-seq data. Nat. Biotechnol. 29 (7), 644-652.

Grinnell, A.D., Narins, P.M., Awbrey, F.T., Hamner, W.M., Hamner, P.P., 1988. Eye/photophore coordination and light-following in krill, Euphausia Superba. J. Exp. Biol. 134, 61-77.

Hempel, H., Hempel, G., 1986. Field observations on the developmental ascent of larval Euphausia superba (Crustacea). Polar Biol. 6, 121-126.

Henze, M.J., Oakley, T.H., 2015. The dynamic evolutionary history of pancrustacean eyes and opsins. Integr. Comp. Biol. 55, 1-13.

Hering, L., Mayer, G., 2014. Analysis of the opsin repertoire in the tardigrade Hypsibius dujardini provides insights into the evolution of opsin genes in panarthropoda. Genome Biol. Evol. 6, 2380-2391.

Jerlov, N.G., 1968. Optical Oceanography. Elsevier Publ. Comp, Amsterdam.

Kawaguchi, S., King, R., Meijers, R., Osborn, J.E., Swadling, K.M., Ritzd, D.A., Nicola, S., 2010. An experimental aquarium for observing the schooling behaviour of Antarctic krill (Euphausia superba). Deep-Sea Res. II 57, 683-692.

King, R., Nicol, S., Cramp, P., Swadling, K.M., 2003. Krill maintenance and experimentation at the Australian Antarctic Division. Mar. Freshw. Behav. Physiol. 36, 271-283.

Kingston, A.C.N., Cronin, T.W., 2015. Short- and long-wavelength-sensitive opsins are involved in photoreception both in the retina and throughout the central nervous system of crayfish. J. Comp. Physiol. A. 201, 1137-1145.

Koyanagi, M., Terakita, A., Kubokawa, K., Shichida, Y., 2002. Amphioxus homologs of Gocoupled rhodopsin and peropsin having 11-cis- and all-trans-retinals as their chromophores. FEBS Lett. 531, 525-528.

Lenz, P.H., Roncalli, V., Hassett, R.P., Wu, L.S., Cieslak, M.C., Hartline, D.K., Christie, A.E., 2014. De novo assembly of a transcriptome for Calanus finmarchicus (Crustacea, Copepoda) - the dominant zooplankter of the North Atlantic Ocean. PLoS One 9 (2), e88589.

Liegertová, M., Pergner, J., Kozmiková, I., Fabian, P., Pombinho, A.R., Strnad, H., Pačes, J., Vlček, Č., Bartůněk, P., Kozmik, Z., 2015. Cubozoan genome illuminates functional diversification of opsins and photoreceptor evolution. Sci. Report. 5, 11885.
Livak, K.J., Schmittgen, T.D., 2001. Analysis of relative gene expression data using realtime quantitative PCR and the $2^{-\Delta \Delta C T}$ method. Methods 25, 402-408.

Loew, E.R., McFarland, W.N., 1990. The Underwater visual environment. In: Douglas, R.H. Djamgoz, M.B.P. (Eds.), The Visual System of Fish. Springer, London, pp. 1-43.

Mazzotta, G.M., De Pittà, C., Benna, C., Tosatto, S.C.E., Lanfranchi, G., Bertolucci, C., Costa, R., 2010. A cry from the krill. Chronobiol. Int. 27 (3), 425-445.

Meyer, B., Martini, P., Biscontin, A., De Pittà, C., Romualdi, C., Teschke, M., Frickenhaus, S. Harms, L., Freier, U., Jarman, S., Kawaguchi, S., 2015. Pyrosequencing and de novo assembly of Antarctic krill (Euphausia superba) transcriptome to study the adaptability of krill to climate-induced environmental changes. Mol. Ecol. Resour. 15 (6) 1460-1471.

Nagata, T., Koyanagi, M., Terakita, A., 2010. Identification and characterization of a protostome homologue of peropsin from a jumping spider. J. Comp. Physiol. A. 196, 51-59.

Oakley, T.H., Huber, D.R., 2004. Differential expression of duplicated opsin genes in two eye types of ostracod crustaceans. J. Mol. Evol. 59, 239-249.

Pattyn, F., Speleman, F., De Paepe, A., Vandesompele, J., 2013. RTPrimerDB: the real-time PCR primer and probe database. Nucleic Acids Res. 31, 122-123.

Pfaffl, M.W., Tichopád, A., Prgomet, C., Neuvians, T.P., 2004. Determination of stable housekeeping genes, differentially regulated target genes and sample integrity: BestKeeper - excel-based tool using pair-wise correlations. Biotechnol. Lett. 26, 509-515.

Porter, M.L., Cronin, T., McClellan, D., Crandall, K., 2007. Molecular characterization of crustacean visual pigments and the evolution of pancrustacean opsins. Mol. Biol. Evol. 24, 253-268.

Porter, M.L., Blasic, J.R., Bok, M.J., Cameron, E.G., Pringle, T., Cronin, T.W., Robinson, P.R., 2012. Shedding new light on opsin evolution. Proc. R. Soc. B 279, 3-14.

Porter, M.L., Speiser, D.I., Zaharoff, A.K., Caldwell, R.L., Cronin, T.W., Oakley, T.H., 2013. The evolution of complexity in the visual systems of stomatopods: insights from transcriptomics. Integr. Comp. Biol. 53, 39-49.

Quetin, L.B., Ross, R.M., 1991. Behavioral and physiological characteristics of the Antarctic krill, Euphausia superba. Am. Zool. 31, 49-63.

Sahoo, P.K., Kar, B., Mohapatra, A., Mohanty, J., 2013. De novo whole transcriptome analysis of the fish louse, Argulus siamensis: first molecular insights into characterization of toll downstream signaling molecules of crustaceans. Exp. Parasitol. 135, 629-641.

Sun, H., Gilbert, D.J., Copeland, N.G., Jenkins, N.A., Nathans, J., 1997. Peropsin, a novel visual pigment-like protein located in the apical microvilli of the retinal pigment epithelium. Proc. Natl. Acad. Sci. U. S. A. 94, 9893-9898.

Tamura, K., Dudley, J., Nei, M., Kumar, S., 2007. MEGA4: molecular evolutionary genetics analysis (MEGA) software version 4.0. Mol. Biol. Evol. 24, 1596-1599.

Teschke, M., Wendt, S., Kawaguchi, S., Kramer, A., Meyer, B., 2011. A circadian clock in antarctic krill: an endogenous timing system governs metabolic output rhythms in the euphausid species Euphausia superba. PLoS One 6 (10), e26090.

Thaben, P.F., Westermark, P.O., 2014. Detecting rhythms in time series with RAIN. J. Biol. Rhythm. 29, 391-400.

Thompson, J.D., Higgins, D.G., Gibson, T.J., 1994. CLUSTAL W: improving the sensitivity of progressive multiple sequence alignment through sequence weighting, positionspecific gap penalties and weight matrix choice. Nucleic Acids Res. 22, 4673-4680.

Townson, S.M, Chang, B.S.W, Salcedo, E, Chadwell, L.V, Pierce, N.E, Britt, S.G, Towner, P, 1998. Honeybee blue- and ultraviolet-sensitive opsins: cloning, heterologous expression in Drosophila, and physiological characterization. J. Neurosci. 18, 2412-2422.

Untergasser, A., Cutcutache, I., Koressaar, T., Ye, J., Faircloth, B.C., Remm, M., Rozen, S.G. 2012. Primer3 - new capabilities and interfaces. Nucleic Acids Res. 40, e115.

Velarde, R.A., Sauer, C.D., Walden, K.K., Fahrbach, S.E., Robertson, H.M., 2005. Pteropsin: a vertebrate-like non-visual opsin expressed in the honey bee brain. Insect Biochem. Mol. Biol. 35, 1367-1377. 